\title{
Optimization of the nozzles' structure in gas well
}

\author{
Zuwen WANG ${ }^{1, a}$, Shasha WANG ${ }^{2, b}$ Yihua $\mathrm{DOU}^{3, \mathrm{c}}$ and Zhiguo WANG ${ }^{4, d}$ \\ ${ }^{1}$ CNPC Chuanqing Drilling Engineering Company Limited, Changqing Downhole Technology \\ Company, Xi'an, 710018, China \\ ${ }^{2,3,4}$ School of Mechanical Engineering, Xi'an Shiyou University, Xi'an, 710065, China \\ awangzuwen1060@sina.com, b shashawang15@163.com, ’yhdou@vip.sina.com, \\ dWangzhiguo77@gmail.com
}

\section{Keywords: Choke; Structure optimization; Flow simulation}

Abstract. High-speed gas in wellhead throttling nozzle carry condensate water and sand, which cause serious erosion to nozzle. Erosion rate with the velocity generally show an exponential growth, the higher the gas velocity inside the nozzle, the more serious erosion. This paper mainly analyze gas fluid flow in nozzle and propose optimization project of nozzle structure. This project try to decrease fluid velocity turbulence structure and erosion under pressure drop and temperature are satisfied.

\section{Introduction}

Oil production technology has greatly improved recovery rate of oil and gas well with the acceleration of large reservoir. Hydraulic fracturing technology plays a very important role in stimulation treatment

${ }^{[1]}$. In the process of fracturing with large displacement and high sand ratio, high speed fracturing liquid carrying sand cause serious erosion damage for control equipment and high pressure manifold wall. Because the pipeline pressures range from a few 10 MPA to hundreds of MPA, once pierced or fractured, it is likely to cause serious consequence ${ }^{[2,3]}$.

Fixed throttle nozzle is an important part of the ground choke manifold in gas well ${ }^{[4]}$. But there is a problem on wear short life fixed of throttle nozzle in practical applications, which seriously affect the gas well productivity and ground choke manifold whole life, so it is of great significance to explore the gas flows through the fixed throttle nozzle. So, in order to effectively control and reduce erosion loss, and improve the service life of the equipment and materials, the scheme of structure optimization of fixed nozzle is proposed.

This paper presents an extensive study and investigation of flow field distribution and wall erosion rate of liquid-solid two phase in fixed throttle nozzle by using Euler- Lagrange dispersion model (DPM).The effect of the diameter and length of nozzles were analyzed considering the flow field distribution and wall erosion rate, then scheme of nozzle structure optimization is determined.

\section{Model description}

Three calculation equations of Fluent are shown as Equation (1), (2) and (3), three equations discrete can get choke flow field distribution. FLUENT for continuous phase solving process is mainly the discretization of three basic equations, which include the mass continuity equation, momentum equation, and energy equation ${ }^{[5]}$.

The mass equation can be written:

$$
\frac{\partial \rho}{\partial t}+\frac{\partial \rho\left(u_{j}\right)}{\partial x_{j}}=0 \quad j=1,2,3
$$

Where $x$ is the axial coordinate, and $u$ is the axial flow velocity.

The momentum equation can be written: 


$$
\frac{\partial}{\partial t}\left(\rho u_{i}\right)+\frac{\partial}{\partial x_{j}}\left(\rho u_{i} u_{j}\right)=-\frac{\partial P}{\partial x_{i}}+\partial \frac{\partial \tau_{i j}}{\partial c_{j}}+\rho g_{i}+F_{i}
$$

Where $p$ is the static pressure; $\tau_{i j}$ is the stress tensor, which is defined as $\square$

$$
\tau_{i j}=\left[\mu\left(\frac{\partial u_{i}}{\partial x_{j}}+\frac{\partial u_{j}}{\partial x_{i}}\right)\right]-\frac{2}{3} \mu \frac{\partial u_{l}}{\partial x_{l}} \delta_{i j}
$$

The energy equation can be written:

$$
\frac{\partial}{\partial t}(\rho E)+\frac{\partial}{\partial x_{i}}\left(u_{i}(\rho E+p)\right)=\frac{\partial P}{\partial x_{i}}+\left(k_{e f f} \frac{\partial T}{\partial x_{i}}-\sum_{j} h_{j} J_{j}+u_{j}\left(\tau_{i j}\right)_{e f f}\right)+S_{i}
$$

Where $K_{\text {eff }}=K_{t}+K$ is effective thermal conductivity, $J_{j}$ ' is diffusion flux of $J$ '. The first three to the right of the equation is the thermal conductivity, the component diffusion term and the viscous dissipation term. $S_{h}$ is a source term that includes other volume heat sources and chemical reaction heat.in the formula, $E=h-p / \rho+u_{i}^{2} / 2$. For the ideal fluid, the enthalpy is defined as:

$$
h=\sum_{j^{\prime}} m_{j^{\prime}} h_{j^{\prime}}
$$

For incompressible gases, it is defined as:

$$
h=\sum_{j^{\prime}} m_{j^{\prime}} h_{j^{\prime}}+\frac{p}{\rho}
$$

$M_{j}^{\prime}$ is the quality score of $J^{\prime}$, which is defined as $h_{j^{\prime}}=\int_{T_{r e f}}^{T} c_{p, j^{\prime}} d T T_{r e f}=298.15 K . F_{i}$ is Gravity force and other volume force , $F_{i}$ also include user-defined source terms or other model source term.

\section{Model establishment and boundary condition setting}

Fig. 1 shows a 2D axis nozzle model with $10 \mathrm{~mm}$ diameter and 100mm length, this model uses tetrahedral mesh and meshing is encrypted at nozzle, as shown in Fig. 2, the grid of overall computational model is 10600, and the number of nodes is 10891 .

Velocity inlet is used at the entrance, pressure outlet is used at the exit, wall adopt stationary wall boundary conditions. The liquid phase is water, and the solid phase is quartz sand, Sand injection rate is the same as the fluid velocity, the quartz sand density is $2600 \mathrm{~kg} / \mathrm{m} 3$, and the particle size is $40-60$ mesh.

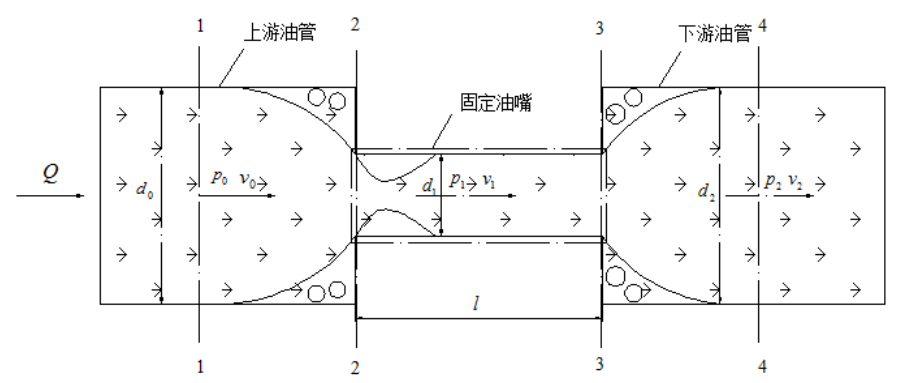

Fig. 1 Constant diameter fixing nozzle 


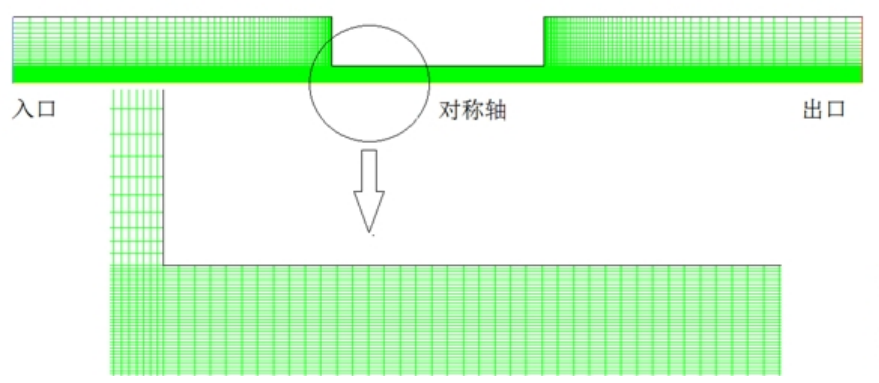

Fig. 2 Constant diameter fixing nozzle meshing

\section{Calculation results and discussion}

Simulation results analysis of constant throttling nozzle. The contour of pressure, velocity, temperature and erosion rate are shown in Fig. 3 (a), (b), (c), (d) respectively. Taking equal diameter nozzle of $10 \mathrm{~mm}$ diameter and $100 \mathrm{~mm}$ length as an example. From the Fig. 3 (a), it can be seen that the pressure change is concentrated in the variable diameter part, and the pressure distribution in the front cavity of the nozzle is even. After the throttling nozzle, the pressure of the back chamber is $15 \mathrm{MPa}$, and the pressure change between the front and back chamber of nozzle is abrupt. Fig. 3 (b) shows that the maximum speed is concentrated in the variable diameter part. Because the erosion rate generally has exponential relation with the velocity, the velocity increasing, the nozzle erosion is more serious. So the more uniform nozzle velocity distribution is, the smaller erosion rate is, the production are more conducive. Fig. 3 (c) show that the outlet temperature changes greatly, in the process of production of gas well, the gas solid two phase fluid change pressure by the nozzle and ensure the stable pressure of natural gas production, temperature reduction is inevitable during pressure drop, because the fluid in the pipe are natural gas, the temperature of natural gas should be higher than 21 degrees to ensure the normal production. Considering solid particle impact ${ }^{[6-9]}$, Fig. 3(d) shows maximum erosion rate occurs in position where the fluid change direction in the nozzle and maximum reaches $0.0214 \mathrm{~kg} \cdot \mathrm{m}^{-2} \cdot \mathrm{s}^{-1}$.

As can be seen from the above simulation results, the flow rate of the equal diameter nozzle at the entrance varies greatly, resulting in greater erosion at the entrance of the nozzle ${ }^{[10,11]}$. However, the temperature at the exit is very large, and when the mass flow increases, the temperature drop may occur freeze (less than $21^{\circ} \mathrm{C}$ ). So, in order to prevent the above, the equal diameter nozzle can be optimized into a reducing-equal-expanding diameter nozzle. 


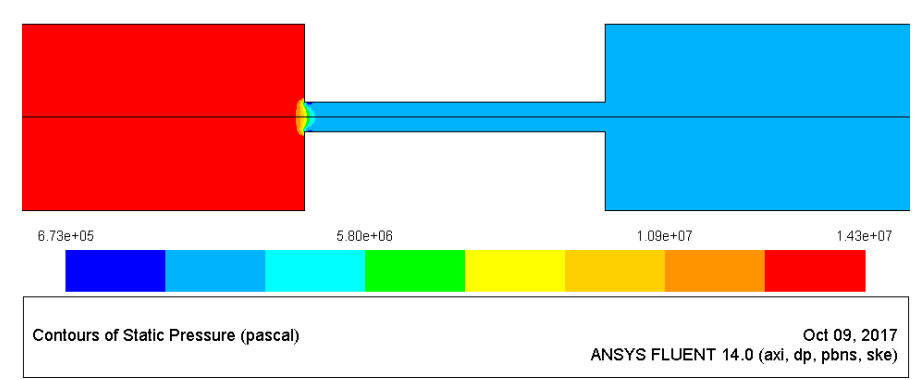

(a) Pressure contour of equal diameter throttling nozzle

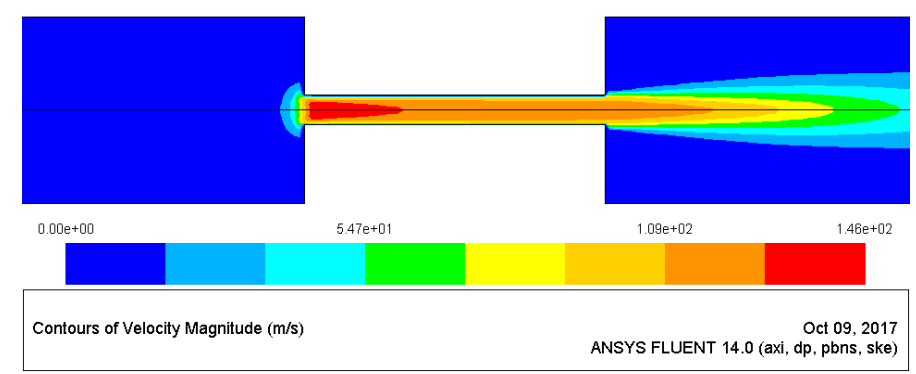

(b) Velocity contour of equal diameter throttling nozzle

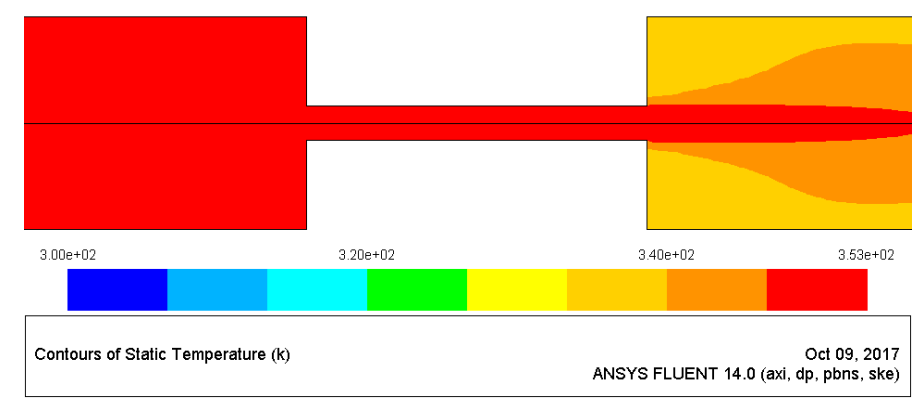

(c) Temperature contour of equal diameter throttling nozzle

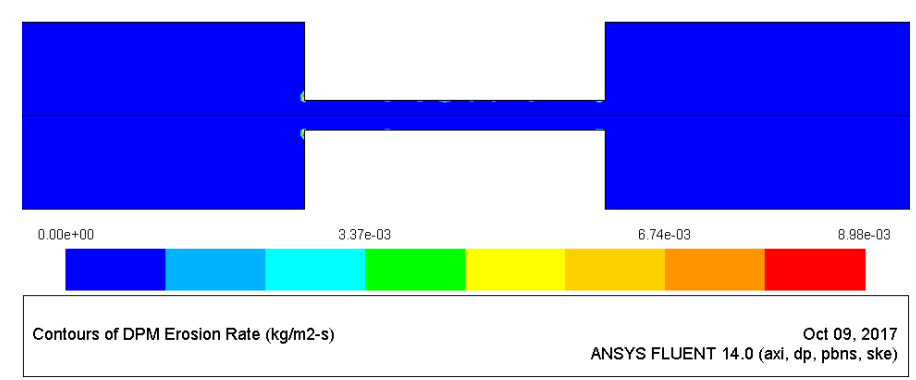

(d) Erosion contour of equal diameter throttling nozzle

Fig. 3 Flow field distribution contour of equal diameter throttling nozzle

Simulation results analysis of variable diameter nozzle. The contour of velocity, pressure, temperature and erosion rate are shown in Fig.4 (a), (b), (c), (d) respectively. Taking variable diameter nozzle of 12-10-10 mm diameter and $100 \mathrm{~mm}$ length as an example. From the Fig.4(a), it can be seen that the maximum speed occurs at the inlet of the nozzle, the maximum speed is much smaller than that of the equal diameter nozzle. Fig.4 (b) shows the maximum pressure drop occurs at the inlet of the nozzle, At the inlet of the nozzle, the pressure drops sharply and the pressure rises gradually after the divergent part. It can be seen from the Fig. 4 (c) that the temperature distribution is more uniform, there is lower temperature drop and the hydrate is not easy to form at the outlet. Fig.4 (d) explains the maximum erosion rate occurs at the inlet of the nozzle ${ }^{[12]}$. There is small erosion rate at the reduced section, and erosion don't occurs at the equal diameter section and the divergent section. 

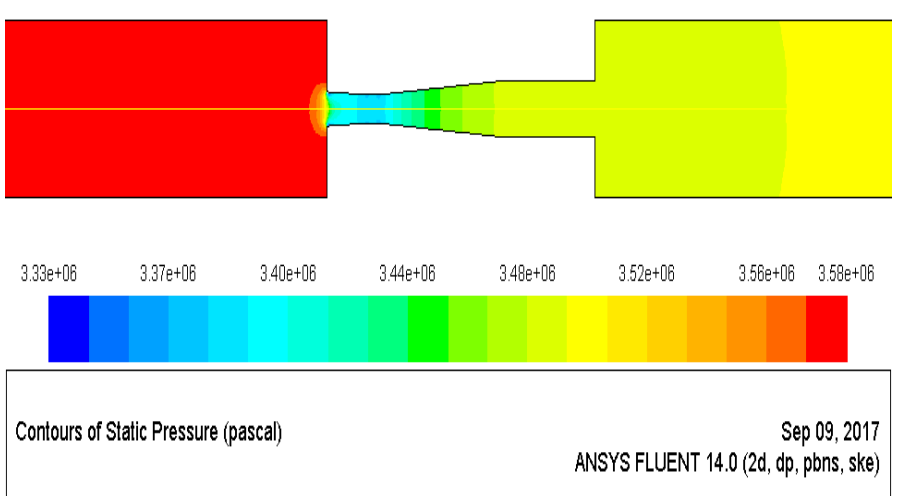

(a)Pressure contour of variable diameter throttling nozzle
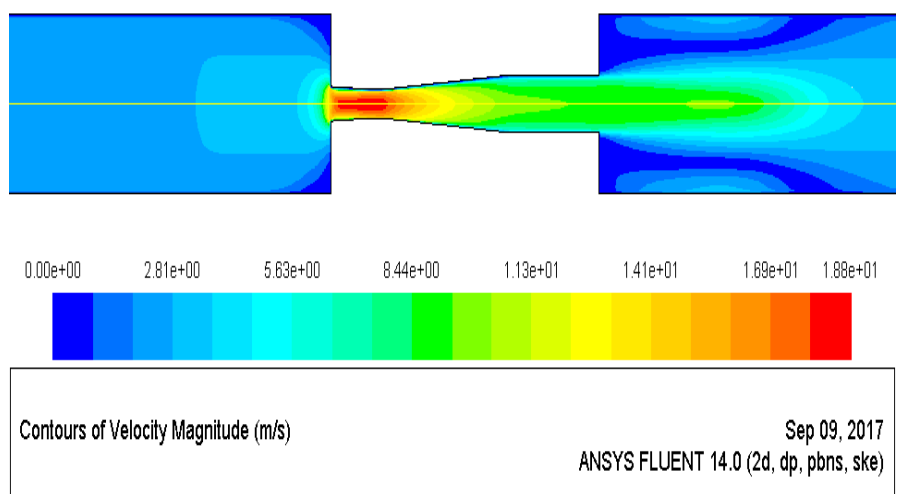

(b) Velocity contour of variable diameter throttling nozzle

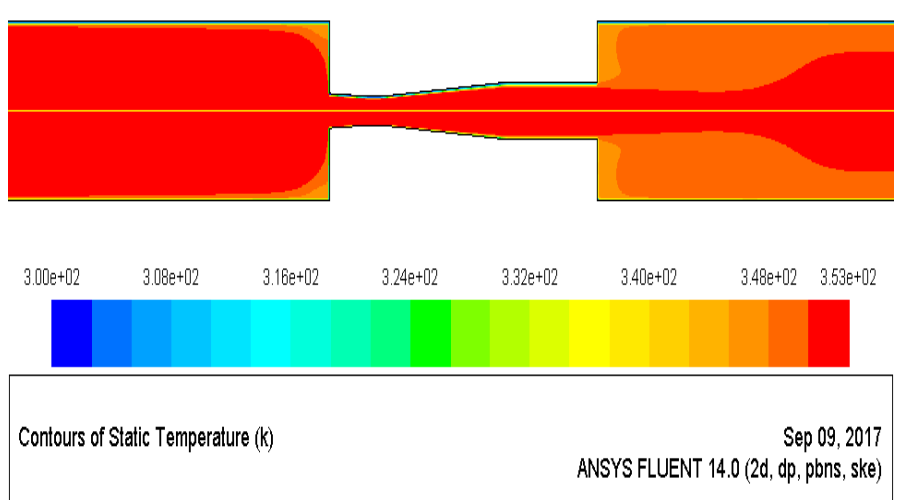

(c)Temperature contour of variable diameter throttling nozzle
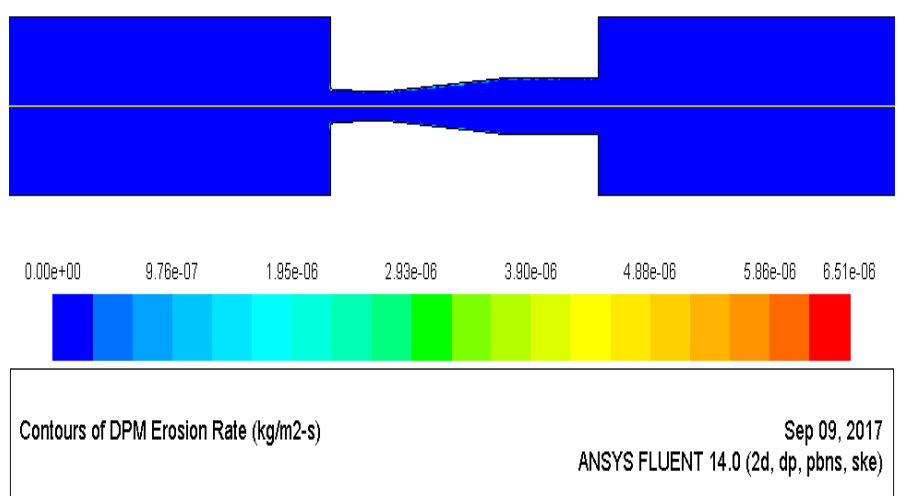

(d)Erosion contour of variable diameter throttling nozzle

Fig.4 Flow field distribution contour of variable diameter throttling nozzle

Simulation results analysis of equal and variable throttling nozzle. To prevent nozzle from erosion damage, the inlet and outlet of nozzle were optimized, taper angle transition is used at the inlet and outlet of nozzle. At the entrance, the inlet velocity is relatively low, taper angle structure can effectively reduce the speed by changing the direction of fluid and the pressure gradient caused and avoid leading 
to wall impact damage caused by fluid with sand.At the exit, taper angle structure can prevent gas free expansion and a direct impact on the wall by changing flow direction of natural gas. Fig.5, Fig.6 shows the comparison of the maximum erosion rate and pressure drop between equal diameter and diverging diameter nozzle. As can be seen in Fig.5, the pressure drop of equal diameter is greater than that of equal diameter nozzle in the two structures, and the pressure drop decreases with the nozzle diameter becoming larger, and the pressure drop changes obviously when the diameter is small. It can be seen from Fig.6, varied diameter nozzle has greater throttle pressure drop and good resistance to erosion compared with the equal diameter structure.

\section{Conclusions}

Considering the effect of flow rate, pressure, and erosion rate of different nozzles by using numerical simulation methods, flow field simulation results are as follows:

(1) Compared with the equal diameter nozzle, variable diameter nozzle has less flow resistance, and mass flow are greater than of equal diameter throttling nozzle under the condition of the same throttle pressure drop.

(2) Maximum erosion rate occurs in position where the flow directions change in the nozzle. there is a big whirlpool, the pressure is relatively low, there may have a certain amount of condensate water, if gas carry with particles and acid gases, the larger erosion corrosion interactions may happen.

(3) Compared to several other nozzle structures, variable diameter nozzle of d10-8-10 has greater throttle pressure drop and good resistance ability to erosion.

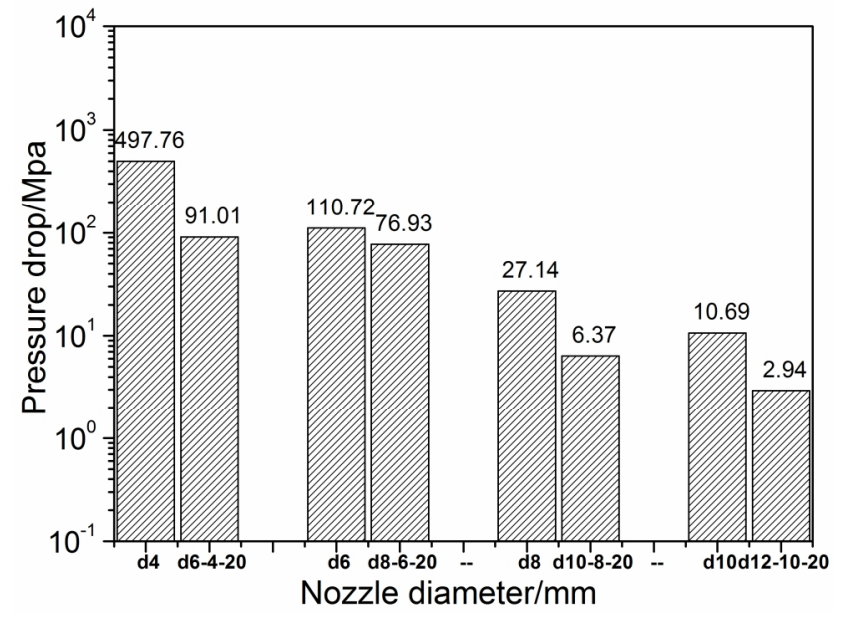

Fig.5 Pressure drop of equal and variable diameter throttling nozzle

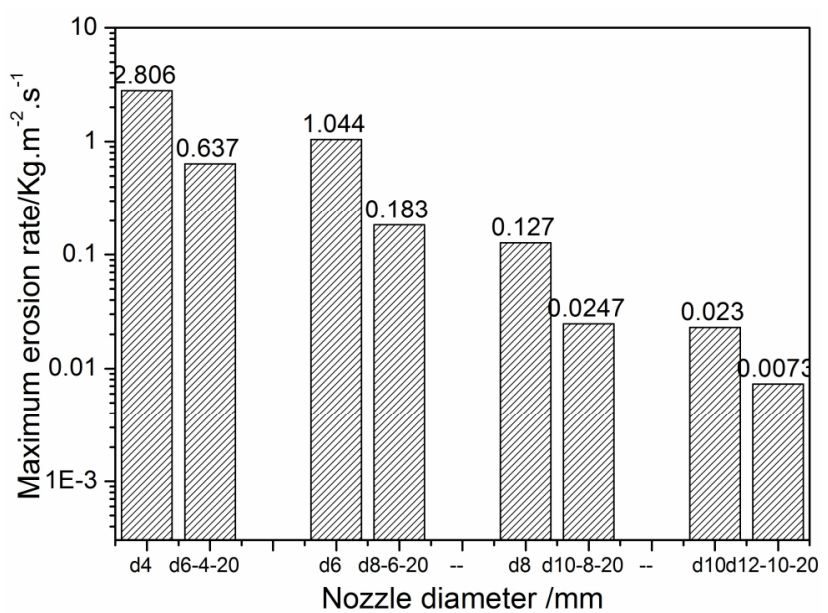

Fig. 6 Maximum erosion rate of equal and variable diameter throttling nozzle

\section{References}

[1] Shouzeng Tian, Gensheng Li, Zhongwei Huang. submitted to Journal of Oil Drilling \& Production Technology, 2008. In Chinese.

[2] Zhiguo Wang, Xiangtong Yang, Yihua Dou, LUO Shengjun. submitted to Journal of Oil Drilling \& Production Technology, 2016, 38(4). In Chinese.

[3] Hongwen Liu, Dengping Liu. submitted to Journal of Natural gas industry, 1990,109(5). In Chinese.

[4] Yuxing Li, Deyong Zhou. submitted to Journal of Oil \& Gas Storage and Transportation,2002, 21(2):15-19.In Chinese.

[5] Chen X, Mclaury B S, Shirazi S A. submitted to Journal of Computers \& Fluids, 2004,33(10): 1251-1272.

[6] Oka Y, Okamura K, Yoshida T. submitted to Journal of Wear,2005,259:95-101. 
[7] Oka Y, Okamura K, Yoshida T. submitted to Journal of Wear,2005,259:102-109.

[8] Mclaury B S, Shirazi S A, Viswanathan V, et al. submitted to Journal of Journal of Energy Resources Technology, 2011, 133(2):180-190.

[9] Malaury B S, Shirazi S A, Shadley J R, et al. submitted to Journal of Proceedings of the SPE Annual Technical Conference and Exhibition. San Antonio: [s. n.], 1997: 977-986.

[10] Okhovat A, Zeinali Heris S, Haj Asgarkhani M A, et al. submitted to Journal of Arabian Journal for Science and Engineering,2014,39(3):1497 1505.

[11] Chen X, McLaury B S, Shirazi S A. submitted to Journal of Computers \& Fluids, 2004, 33(10): 1251-1272.

[12] Chen X, McLaury B S, Shirazi S A. submitted to Journal of Wear, 2006, 261(7): 715-729.

[13] Zhang Y, McLaury B S, Shirazi S A. submitted to Journal of Journal of Fluids Engineering, 2009, 131(3): 031303. 